\title{
Flexibility and egalitarianism: musical insights from hunter-gatherers
}

\author{
Alice Rudge \\ University College London
}

Among egalitarian hunter-gatherer groups across the African continent, musical practices and egalitarian socialities are argued to be mutually implicated with one another. Southeast Asian huntergatherers also practice egalitarianism, however, and their musical practices represent a seeming anomaly alongside those of many African hunter-gatherer groups. Discussion of 'hunter-gatherer musics' that includes Southeast Asian perspectives has therefore been absent, even though cross-cultural, continent-spanning research with hunter-gatherers is common on topics such as politics, economics, and subsistence. Insights into egalitarianism can be gained through attention to the diversity in huntergatherer musical practices. This discussion of Ju|'hoansi (Namibia) and Batek (Malaysia) musical practices demonstrates that egalitarianism can be understood in terms of its flexibility.

\section{Keywords}

hunter-gatherer; egalitarianism; polyphony; aesthetics; diversity; flexibility

\section{Music in hunter-gatherer research}

Though the usefulness of the category of 'hunter-gatherer' has been questioned over the years (see Guenther 2007; Lee 1992; Testart 1988 for summaries of these debates), cross-cultural theorising about 'hunter-gatherers' has been common since the 1966 Man the Hunter Conference (for example Bird-David 1992b, 1996a; Dahlberg 1981; Kelly 2013; Kent 1996; Lee and DeVore 1987). While allowing for heterogeneity, researchers working with hunting and gathering peoples around the world have proposed that particular orientations are, to varying extents, shared by diverse hunter-gatherer groups. For example, egalitarianism and sharing are Alice Rudge, alice.rudge@ucl.ac.uk, Institute of Advanced Studies, University College London, WC1E 6BT 
theorised by Woodburn (Woodburn 1982, 2005), modes of relating are discussed by Bird-David (Bird-David 1992a, 2017a, 2017b), relationships with the environment are theorised by Ingold (2000) and, more broadly, particular ways of thinking and acting are said to be fostered by participating in the practices of hunting and gathering (Barnard 2002; Widlok 2016). However, perhaps because of the vast diversity in the musical practices of hunting and gathering peoples, discussions of 'music' have been largely absent from these broad, continent-spanning theoretical discussions, even though in other spheres, insights from ethnography with hunting and gathering peoples have been influential (for example Sahlins 1998's influence on economic history).

In the light of this diversity, however, might it be possible to consider the varied musical practices of egalitarian hunting and gathering peoples alongside one another? Indeed, despite the temptation to search for commonalities across hunter-gatherer groups, some have also raised the idea of 'intracultural variability' among hunter-gatherers as a research topic 'in its own right' (Bird-David 1996b: 298; cf. Kent 1996; Widlok 2001b, 2001a). Bird-David suggests topics within which such variety could be sought, listing 'variations in settlement patterns, mobility and hostility, hunting success and effort, plant use, children's participation in food-collection, women's fertility, gender segregation, marriage and kinship patterns, hunting ceremonies, and belief and ritual systems' (Bird-David 1996b: 298). Still, those practices that might in English be described as 'musical' are absent from her list. What, then, might be gained from bringing music into the discussion on diversity among hunting and gathering peoples?

When it comes to Southeast Asian hunting and gathering groups, very little has been written on their musics at all. This is to the extent that Roseman's monograph on the horticulturalist Temiar of Malaysia (1993) has become representative of the indigenous musics of Southeast Asia (Grauer 2006: 18, 49). When it comes to Southeast Asian groups who practice hunting and 
gathering such as the Maniq (Thailand), Batek (Malaysia), Agta (Philippines), or Jahai (Malaysia), information is thus far relatively lacking. In contrast, many African hunter-gatherer groups are often discussed in terms of their musical practices. BaYaka groups in the tropical forests of the Congo Basin (Arom 1984; Kisliuk 1998; Fürniss 2006; Lewis 2002, 2009, 2013; Oloa-Biloa 2017; Rouget 2011; Weig 2015) have been of particular interest to anthropologists and ethnomusicologists, as have San groups in southern African regions (England 1967, 1995; Marshall 1969; Katz 1982; Katz and others 1997; Keeney and others 2016; Low 2015; Olivier 1998, 2001, 2004, 2009; Widlok 1999, 2001b). Many of the scholars working with African hunting and gathering groups argue that there are profound links between egalitarianism, musical style and participation, in particular group dance and polyphony, or the interweaving of multiple vocal parts (England 1967: 60; Guenther 1999: 138; Katz 1982; Lewis 2009, 2013; Oloa-Biloa 2017; Rouget 2011; Weig 2015). Thus far, therefore, perspectives that draw on ethnography with Southeast Asian hunter-gatherers are missing from discourses on the musics of hunting and gathering peoples, which tend to focus on particular geographical areas where peoples' musical practices are more overt, and include frequent large-scale ritual music and dance events. Though this work is highly important, viewed on its own it may run the risk of obfuscating the fact that egalitarian hunting and gathering groups around the world participate in hugely varied musical practices.

In addition to 'single-culture' studies, cross-cultural comparison of African groups spanning vast geographic divides has also been popular, particularly on the topic of polyphony and its relation to 'social structure'. Though his deterministic approach has largely now been rejected amongst ethnomusicologists, Lomax was a famous proponent of the comparative method. While his arguments regarding songs as calling up 'webs of relationships' (Lomax 1971: 6) are still of use today, his argument that there is a relationship between 'the level of complexity of a culture' and 
its musical structure (Lomax 1971: xii) is reflective of how comparative studies have mired studies of hunter-gatherers more broadly by either erasing diversity, or turning cultural diversity into an evolutionary sequence (Kelly 2013: 3). In spite of this, elements of Lomax's arguments regarding the link between social structure or cultural 'value' (Grauer 2006: 46) and musical structure were taken up by Frisbie, who argues for the usefulness of music in reconstructing 'culture history' (1971). Later, based on analyses of polyphony among Aka and Ju|'hoansi, Grauer makes the argument that musical evidence might link these two groups evolutionarily (2009, critiqued by Cross 2006), a line of thinking discussed by Poole in his comparison of Pygmy and Bushmen rhythmic timelines (see also Poole 2018). Cross-cultural work has also been undertaken by Olivier and Fürniss (1999), who argue that Aka and Ju|'hoansi peoples conceptualise counterpoint differently, and that $\mathrm{Ju}$ |'hoansi music is therefore in fact not true polyphony. Debates on what makes true polyphony, and whether or not this has evolutionary implications are far beyond the scope of this article. At this point it is important to note that whatever their motive, ethnomusicological and anthropological work which looks in depth, and across cultures, at the musical practices of these diverse African groups has been common.

Also common is the valid assertion that a connection is to be made between polyphony, dance, egalitarianism, and a hunting and gathering way of life. Scholars of BaYaka hunting and gathering peoples do so using ethnographically-situated, nuanced, and contextualised approaches. Lewis has been a proponent of this approach, arguing that Mbendjele BaYaka hunter-gatherers' dance and polyphonic singing has the power to 'seduce' (Lewis 2013: 45) people into having certain egalitarian values through habitual participation. As such, musical practices offer a privileged window into 'foundational cultural schemas'. Through learning how to join in with polyphonic singing and communal dancing, individuals make 'aesthetic decisions', which foster skills necessary for egalitarian life more broadly, such as in the spheres 
of politics and economics (Lewis 2013:63). The ‘intense cooperation' involved in polyphonic singing inculcates 'the unspoken grammar of interaction' which 'is the dynamic of daily life in this egalitarian society' (Lewis 2012: 100). Scholars such as Finnegan (2013) writing on BaYaka people, Weig (2015) working with Baka people, and Power (2015: 336), writing on the Hadza (Tanzania), draw on such ethnography, and on Woodburn (1982; cf. Endicott and Endicott 2008), in understanding egalitarianism as worked at through achieving a balance between cooperation and autonomy.

These ethnographies give brilliant and important insights into the workings of musical practices among these groups. However, there are hunter-gatherer, and post-hunter-gatherer groups in other parts of the world, living broadly egalitarian lives, who participate in ostensibly very different musical practices. Whilst not arguing against the idea that participating in polyphonic music and dance is a highly important way in which egalitarian aesthetics are fostered, a discrepancy arises when Southeast Asian groups are brought into the picture. If there are modes of being egalitarian that are common to hunter-gatherer groups, and these are inculcated by particular styles of musical structure and participation, why do some hunter-gatherer and former hunter-gatherer groups seemingly have such radically different musical practices? Evolutionary questions aside, if 'music might best be interpreted as a communicative medium adapted for the efficacious management of social relations' (Cross 2006: 59), how might it be understood that groups as diverse as the BaYaka, Ju|'hoansi, and Batek recreate egalitarianism in the present day? Separately, how do musical practices play a role here? Might there therefore be ways other than polyphony through which people can 'cooperate autonomously' during the musical process? Might differences in musical process be informative of subtle differences in the ways in which egalitarianism is manifested? Alongside these deliberations, and being mindful of Nettl's famous assertion that 'each social group has its music' (2001: 465), might there not also be some musical 
connections between the practices of some of these diverse 'social groups', as implied of in other domains by scholars such as Barnard (2002), Widlok (2016), Ingold (2000), and Bird-David (1992b, 1996b; 1999; 2017a)?

To answer these questions, this paper focuses on musical practices of members of an egalitarian, hunting and gathering group who thus far have been little included in discourses on the musics of hunting and gathering peoples: the Batek (Peninsular Malaysia). I draw on long-term and ongoing ethnographic fieldwork conducted with Batek De? (henceforth abbreviated to Batek) people in Pahang State. The Batek are one of the approximately 20 cultural-linguistic groups of Orang Asli ('Original People’), of Peninsular Malaysia (Endicott 2016). The most recent estimate of their population puts their number at over 1,500 people (Endicott et al 2016:100). The fieldwork on which this paper draws spanned periods between March 2014 and August 2018 , totalling over eighteen months, with the majority of the fieldwork time taking place between February 2014 and July 2015. Fieldwork was conducted in the Tembeling and Kechau watersheds in Jerantut and Lipis districts respectively. The methodology used was participant observation, and fieldwork was conducted in Batek. Due to the informal and intimate nature of Batek camps, time was spent with people of all age groups and genders. Time was also spent among groups with varying mobility patterns, reflecting the diversity of Batek approaches to this: some groups and individuals may spend more time in the forest, and others may spend more time in semi-permanent settlements, patterns which may also change across a person's lifetime. Time was also spent with people who spend more time taking part in casual wage labour such as tourism, trade, or working on oil palm plantations, and those who take part in these activities less frequently, instead spending more time hunting and gathering. When discussing Batek ethnography, I also make reference to Endicott's earlier published writings (1979), and to his audio recordings made in Kelantan and held at the RWAAI Archive at the University of Lund 
(Kirk M. Endicott Collection). Throughout the text I specify whether or not insights are gained through participant observation ethnographic fieldwork or through reference to Endicott's previous works.

While, given my ethnographic work with the Batek, my focus on the Batek provides 'ethnographic concreteness' (Bird-David 2017:211), I discuss Batek ethnography with reference to another hunting and gathering (and post-hunting and gathering) egalitarian group: the $\mathrm{Ju}$ |'hoansi (Namibia and Botswana). My research into Ju|'hoansi musical practices has made use of the many published ethnographies (on groups dwelling in both Namibia and Botswana), and archival recordings held by the British Library, made by Emmanuelle Olivier in the Nyae Nyae Conservancy, Nambia, in 1993,1995, and 2001 (shelf mark C1709). Based on this research, I propose suggestions for how the processes involved in making 'hunter-gatherer musics' can be discussed in such a way as to learn from the vast diversity between groups, particularly regarding the varied ways in which hunting and gathering peoples might recreate egalitarianism through their musical practices. An approach that allows for these musical differences to co-exist is needed, whereby these differences in musical practices themselves can inform arguments of what 'music' can do (Bird-David 1996b: cf.; Kent 1996; Kelly 2013).

\section{The problem of comparison}

Given the huge heterogeneity of different hunter-gatherer groups and the highly varied musical practices of the two groups this paper focuses on, it would be reductive to come up with one single unified 'theory' of music, or of a single overarching argument linking hunter-gatherer musics around the globe. Indeed, even the term 'music' is itself problematic, given that this abstract concept has been shown not to be universal (Nettl 2001; Rudge 2017; Seeger 2010). For example, rather than to 'music', the Batek refer to 'sound' (klin), a word which is inclusive of 
both what in English would be termed 'musical' and 'non-musical' sounds, as well as the specific activities of playing the flute, playing the mouth harp, or singing (activities which are each demarcated lexically, but not grouped under an abstract concept of 'music'). Given this fundamental problem, comparison of 'musics' is inherently complex. Furthermore, the idea of cross-cultural comparison between hunter-gatherers is one with a long and turbulent history. As Bird-David correctly points out, the notion that 'all modern hunter-gatherers will be the same' should not be taken seriously (cf. Kelly 2013), and yet many argue for shared traits amongst hunter-gatherer groups, even though who gets to be included in the category of 'hunter-gatherer' is itself up for debate (cf. Roscoe 2002: 158, 160; Kelly 2013: xvi). How, therefore, to begin to theorise the level of intracultural variability found in musical practices across diverse hunting and gathering groups? When considering such variation and diversity, especially given the ways in which most people today combine hunting and gathering with wage labour, trade, or smallscale agriculture or horticulture, arguing for their commonalities might seem totalising.

Given these problems of categorisation, and hence comparison, both on the level of 'music' and of 'hunter-gatherer', and as a result of my methodology (which makes mixed use of archival research, ethnographic work done by others, and first hand field research), I draw on Strathern in thinking 'relationally' (Strathern 2002:xv), yet necessarily 'partially' (Strathern 2004). A project such as this involves 'scale-switching', a process that inherently 'creates loss', as 'each single element that appears to make up the plurality of elements seen from a distance on close inspection turns out to be composed of a similar plurality that demands as comprehensive a treatment' (Strathern 2004: xv). This results in the potential for 'endless kaleidoscopic permutations' (Strathern 2004: xvii), depending on how you group and re-group the materials. Any comparison will thus result in a level of decontextualisation, and furthermore, many details will be missed as a result of considering the musical practices of one group, as represented by a 
collection of ethnographies and recordings based on past research, sometimes decades old (Ju|'hoansi), in the light of first-hand and more immediate and recent insights from another (Batek). The process of editing and selection involved in a comparison such as this may just as easily result in everything either seeming 'partial', or alternately seeming 'connected' (Strathern 2004: xx). However, a comparison that recognises these limitations can be 'an interruption, a refusal of connection to show the gaps through which we can rethink our categories. It creates "the hesitation that makes one pause (the thought that is already an act), in order to allow a second thought"” (Tsing 2014: 223; quoting Strathern 2002: xvi). The aim of this paper, therefore, is to use the 'hesitation' that one might feel in comparing such different musical practices, to shed light on situations 'forced awkwardly into comparison' (Tsing 2014: 223).

In awkwardly putting the distinct processes by which these two groups both practice 'music' and egalitarianism together, I therefore ask what new thinking might emerge on the musical practices of hunting and gathering peoples? In answering these questions, I hope to avoid either 'collaps[ing]' (Strathern 1987: 286) elements of these diverse musical practices into sameness, or ignoring one at the expense of the other. As Kelly has argued, 'generalizations should not mask underlying variability; rather, they should be steps toward understanding it' (2013: 22). I therefore structure this article not in terms of a single linear argument, but as a kind of 'holding place' for ideas (Le Guin 2006: 165-66). Given the diversity of musical practices in huntergatherer groups, there could not be one single, or exhaustive, theory whereby 'hunter-gatherer musics' fulfil one single role, or have a unified nature.

Indeed, even removing the problem of comparing the practices of peoples who dwell in different continents, it would be difficult to argue this with regards to only one group (if it is possible to even define one 'group'). Widlok's point about Hai ||om trance dancing is applicable here- 
trance dancing does not fulfil one single function in a neatly interlocking system. Rather, the experiences of each individual leading up to that moment all go in to constructing that moment, and 'all these elements can be relevant 'nodes' in the process by which residents of a camp relate to one another' (Widlok 1999: 249-50). Similarly, regarding the Batek's musical practices, there is no one single function that they fulfil. However, considering the musical practices of both the Batek and $\mathrm{Ju}$ |'hoansi alongside one another as processes rather than as reified musical cultures (cf. Widlok 2001a: 367), it becomes evident that there are 'nodes' that can be considered in the light of one another, even though they are far from being the same. Recognising, therefore, that any connections between such 'nodes' will be inherently partial, in the following paper I place them alongside one another, with the understanding that if they were rearranged differently, different conclusions might be drawn. Rather than being the final word, I hope this paper can form the basis for future discussions on the diversity of the musics of hunter-gatherer peoples. The sections that follow should thus be thought of as 'nodes' within different musical activities of Batek and Ju|'hoansi peoples, with the knowledge that this is not — and could never be - an exhaustive or definitive account.

\section{Musical participation and structure}

What are the processes by which people participate in music together? How do people relate to one another, or learn to cooperate, using the sounds of the music itself?

Among Batek people in Pahang, everyday singing and musical instrument playing are more often than not solo activities, in the sense that though more than one person may be present, the playing or singing is often done by only one person. Sometimes, two people might play instruments at the same time, for example if one is teaching the other. Though occasionally a Batek instrument player might say 'do it like me' (di? meyhcy ye?), inviting someone to play the flute or the mouth harp with them, they will not necessarily be expected to play in unison. In 
fact, even if they are playing simultaneously, each player may play their own tune, which may at moments be in sync with what the other is playing, but at others drift apart. People are most likely to play musical instruments if lazing around on a hot afternoon, or in the evening when soothing children to sleep, or late at night. There will be no particular audience; the people around might be going about other business, chatting or sleeping. According to Endicott (1979: 141-55), during his fieldwork in the 1970s, Batek people in Kelantan would also take part in large group-singing sessions once or twice a year, with the aim of communicating with the superhuman beings. Other singing sessions were organized sporadically (a few times a year) if someone was 'desperately ill, or if large numbers of people were desperately ill' (Endicott 1979:150).

In everyday musical practices, it is easier for two singers to be at the same pitch than two instruments (as each individual instrument will have a slightly different pitch), and so it is more likely that a couple of Batek people might sing together in unison than play instruments in unison when engaging in casual music-making. Harmony is not used in either casual singing or playing musical instruments, and there are no defined parts. Singers and players may start or stop whenever they feel like it, and anyone may interrupt with their own line that may or may not match the other participants'. Everyday singing seems to happen informally alongside other activities that people get on with as part of daily life. In general this is also the case for other activities that might be described as 'ritual' among the Batek (Endicott 1979: 22), and other Orang Asli peoples of Peninsular Malaysia and Thailand (cf. Kricheff and Lukas (2015) on the Maniq, Howell (1989) on the Ceq Wong). In short, both singing and musical instrument playing fit in with the flow of conversation and other activities, rather than being something that is marked out in performance, though particular sounds and songs may be remembered as special. Structurally, songs are similar to the sounds played on the flute and the mouth harp, where a 
short melodically distinctive and memorable motif is repeated over and over again, until the player decides they want to stop.

This is also the case in the more organised shamanic singing sessions discussed by Endicott, where 'the lines can be repeated any number of times' (1979: 57). In these shamanic singing sessions, he also writes that "perhaps the most common pattern is to have variable lines of verse alternating with a fixed line of refrain. When more than one person sings, the leader usually starts the verse, and the 'chorus' joins in a few beats behind him, either repeating what he has sung or producing some variant of it which takes off from his first few words' (Endicott 1979:144). Referring to one of his own recordings made with Batek people in Southern Kelantan, Benjamin has described the effect of this as a 'disordered hum' (Benjamin 2019: 90). Such sessions also made use of the log drum, which is used to beat the rhythm for dancers (for example, as recorded by Endicott in 1971 and 1981, and referenced in Endicott 1979: 152). Despite the fact that more people were participating in singing together during these sessions in a loose call-and-response, based on Endicott's recordings and descriptions, it is also apparent that, like in more everyday singing, the lines sung by each individual singer are relatively autonomous. Individuals join in with their own lines in an ad hoc manner.

Among the $\mathrm{Ju} \mid$ 'hoansi, the situation is very different—not least because musical practices often involve large groups and take place frequently. Though there has been some debate over whether or not the medicine dance songs are true polyphony (Grauer 2009; Olivier and Fürniss 1999; Olivier 1998), it is safe to say that the singing heard in Ju|'hoansi medicine dances consists of a complex pattern of interweaving voices. Though, like the Batek, songs and instrumental music are characterised by short repeating motifs, Olivier has described how for the Ju|'hoansi 'to the ear, in reality, several melodic lines can be distinguished, proceeding by contrary motion and following independent rhythms' (Olivier 1998: 359). In many of her recordings deposited at the British Library, Olivier uses 're-recording' (Arom 1976), which involves asking individuals 
to sing their parts over a recording of the full version (which they listen to in headphones) in order to capture each part clearly. This enables different vocal lines to be isolated 'whilst locating their points of overlap' (Olivier 1998: 359). These recordings help to show how 'melodic fragments [which] repeat at more or less regular intervals (the period), but appear each time in different variations' (Olivier 1998: 360). Based on her research, even if not classified as true polyphony, it nonetheless appears that the combination of interlocking tessituras and the development and repetition of motifs, are part of what characterises $\mathrm{Ju}$ |'hoansi singing and musical instrument playing.

Perhaps the most profound differences between the musical practices of these two groups can therefore be found in these distinct ways people cooperate through music, and participate together in the musical process. Whether or not Ju|'hoansi music is polyphonic, their medicine dances are certainly characterised by the use of interlocking contrapuntal melodic parts, where, like BaYaka peoples, individuals learn to cooperate autonomously by slotting their own voice amongst the other autonomous singers' parts. This is far from the case for the Batek, where singing and playing musical instruments are more individual. With the exception of the relatively infrequent example of shamanic singing sessions held in the 1970s-80s in Kelantan, Batek singing very rarely involves different parts, and when it does, the parts are not interlocking, but are in an ad hoc, loose, call-and-response or unison style. Thus, while Ju|'hoansi medicine dances are frequent and involve large numbers of people (Marshall 1969), Batek singing sessions, though they involved many people, took place infrequently. Everyday Batek musicmaking in Pahang is more often a solo activity, though it may happen in the company of others.

\section{Musical aesthetics \& affect}


Why are certain combinations of sounds considered good, beautiful, affective, or effective? I describe below two affective processes by which musical practices become significant and powerful: the Batek emotion concept of ha?ip, and the Ju|'hoansi concept of $n \mid \mathrm{om}$.

Among the Batek, the evocation of ha?ip is a marker of how 'good' or 'beautiful' (bt?et) the evocative source is. Such judgements apply particularly to songs and the sounds played on musical instruments. Harip is an emotion that is difficult to lexicalise in English, but it encompasses feelings of longing, yearning, desire, and love. It is often tinged with nostalgia, or a sense of absence, of missing someone or something. Though harip is a pleasurable emotion that Batek people seek out, if the feeling becomes too intense, or is unresolved, it can be fatal. In Batek, emotions are said to be felt in the heart (klayes). If someone feels too much ha?ip, it is described physically as 'pain in the heart'. Whether or not something makes one feel ha?ip therefore becomes a proxy for whether or not it is 'good' or 'beautiful'. Feelings of ha?ip thus become associated with yearning for the past, which people often describe in terms of an ideal, $b t$ i $t$ representation of what the forest was like. At the same time ha?ip is forward-looking, encouraging people to evoke pleasurable feelings of ha?ip, or to resolve dangerous ones. ${ }^{1}$

Harip is thus the desired emotional response to playing musical instruments and singing. Just as the sounds, sights, or smells of the forest are considered 'good' and 'beautiful' (or bt?et) when they make you ha?ip, whether or not the emotion of ha?ip is evoked by singers or instrument players becomes a marker of how bt?et the sound or song was. In 1970s Kelantan, if a song was bt?et it would have shamanic efficacy (Endicott 1979:144) As songs and the sounds of musical instrument playing are shared around, they do not lose associations with particular memories. Connections between people, place, and memory are therefore foregrounded, as songs become powerfully associated with people who sung them, places where they were sung, and

\footnotetext{
${ }^{1}$ Based on ethnographic fieldwork with the Batek
} 
memories of times spent singing. Such connections are different for different individuals, and yet as a result of the shared lives that people lead, many meanings may also be shared (cf. Rudge in Press 2019). Through ha?ip, the sensations of the forest and their recreation on musical instruments and in songs, take on associations with an 'ad hoc', 'plurality' of persons (BirdDavid 2005: 211), which are constantly changing. Just as Bird-David has described the shared eating of meat as 'regenerat[ing] closeness' among Nayaka people (2005), among the Batek the sharing in the experience of song, musical instrument playing, or other sensory experiences regenerates closeness between individuals linked through webs of memory that these evoke. At the same time as being individual, focusing on personal memories and associations, ha?ip is also communal, evoking shared understandings of the forest (hop) as the ideal representation of 'good' and 'beautiful' (bt?et) (see also Lye 2005).

Participating in musical practices such as singing and playing musical instruments is therefore used to evoke and negotiate ha?ip. Through its physical manifestation in the heart, these practices deeply link people, places, experiences, and memories in such a way that is inclusive and flexible, both autonomous and communal, and inextricably linked with the forest itself. At the same time, balance must be sought by avoiding ha?ip that is 'too much' - and as such avoiding the potential pain of harip sets out guidelines for maintaining individual autonomy while sharing deep bonds with others. Feelings of ha?ip therefore powerfully link people, places, memories and non-humans. Negotiating ha?ip also sets up guidelines for appropriate behaviour, as relationships between people are explicitly framed in terms of ha?ip (Rudge in Press 2019). According to Endicott (1979:145), in 1970s Kelantan, singing was also an important way to induce trance, which was described as a kind of 'forgetting', and did not involve a complete loss of consciousness (1979:149). In everyday Batek singing, however, trancing does not occur.

Ju|'hoansi people explicitly link song and healing, which the Batek in Pahang currently do not. However, in 1970s Kelantan, people did use singing for healing, as seen in a song 
recorded by Endicott in 1971 that was to cure a man who was sick with tuberculosis (1979:150). The medicine dance, or trance dance is an important part of everyday life. Recordings of healing songs used for this purpose make up the majority of the songs which are included within Olivier's collection (British Library C1709), and according to the recordist, these represent almost half of the entire Ju|'hoansi musical heritage (1998:364). In ethnographic representations of the Ju|'hoansi, across time periods and geographical locations, the healing dance is described as a way to bring communities together - to heal not just individuals who are sick, but also to heal the group as a whole and promote connectedness: 'for the Kung [Ju|'hoansi], healing is more than curing, more than the application of medicine. Healing seeks to establish health and growth on physical, social, and spiritual levels; it involves work on the individual, the group, and the surrounding environment and cosmos' (Katz 1982:33). Just as evoking the emotion of ha?ip generates closeness between individuals and with the forest-perhaps the emotional role of trance and healing can be seen in a similar light among the Ju|'hoansi.

In order to reach trance, and hence to be able to heal, women's singing and men's dancing are used - their combination 'heats up' $n \mid$ om — a kind of 'force' or 'energy' (Katz 1982; cf. Marshall 1969; Katz and others 1997; Biesele 1993; Lee 2003). N|om is invisible, 'it is not diffuse in the universe, nor is it loose in the air' (Marshall 1969: 351). It is 'strong', powerful and capable of causing death if its strength is too much. Many things can contain $n \mid$ om, such as 'diverse animals, plants, and other objects' as well as 'the bodies of the n/omkxaosi or 'curers"' (Biesele 1993: 81), but for healing it has to be activated with singing and dancing. When the $n \mid$ om is boiling, healers can go into trance and begin healing. Like ha?ip, $n \mid$ om manifests itself in bodily sensation:

'N|um [n|om] is put into the body through the backbone. It boils in my belly and boils up to my head like beer. When the women start singing and I start dancing, at first I feel quite alright. Then, in the middle, the medicine begins to rise from my stomach. After that I see all the people like very small birds, the whole place will be spinning around, and that is why we run around. The trees will 
be circling also. You feel your blood become very hot, just like blood boiling on a fire, and then you start healing'

[Unidentified Ju|'hoan trance dancer, quoted in Lee (2003: 115)]

'In your backbone you feel a pointed something and it works its way up. The base of your spine is tingling, tingling, tingling, tingling. Then $n \mid$ om makes your thoughts nothing in your head'

[Kxao $\neq$ Oah, a healer from |Kae|kae, Botswana quoted in Katz, Biesele and St Denis (1997: 19)] During the healing dance, men flirt with the dangerous power of fire by coming close to it. This 'hot' role of men's dancing complements the 'cold' of women's power. Through this balance, $n \mid$ om can be 'correctly' heated, which causes it to boil up from the men's bellies into their spines and heads and out to the tips of their fingers where it may be used to draw sickness out of another person's body' (Biesele 1993: 79). A good dance is described as 'hot' (khui) - and in $\mathrm{Ju} \mid$ 'hoansi, the same word $k u$ ' $u$ is used for 'to burn' and 'to cure' (Biesele 1993: 80). Heating the $n \mid$ om correctly is essential — it cannot be 'too hot' — the intensity of the women's singing determines the depth of the trance (Katz 1982: 47). Just as too much ha?ip can be fatal among the Batek, incorrectly controlled $n \mid$ om can also be fatal—and indeed, in order to reach the state of trance, you must be willing to face death: 'when potential healers can face this fact of their death and "willingly" die, the fear of num can be overcome, and there can be a breakthrough to kia [trance]' (Katz 1982: 45).

Among the Ju|'hoansi, the ways people understand the power and affect of music is tied in with conceptualisations of male and female power. This dichotomy is not reflected in Batek conceptualisations of gender relations, though comparable flows of male and female power have been described among central African hunter-gatherer groups (Finnegan 2013, 2015; Lewis 2008; Power 2015). Biesele links these ideas about mediating between hot and cold, and male and female found in discourses on $n \mid$ om with other Ju|'hoansi concepts, such as $n$ !'ao, 'a complex of ideas relating to atmospheric conditions, men's hunting, women's childbirth, and the great 
meat animals', which is 'built on opposition between the desirable cool, rainy weather, and that season of the year when great heat, dryness, and night-time cold conspire to make the Ju|'hoansi hungry and uncomforatble’ (Biesele 1993: 81).

Common to both Batek and Ju|'hoan discourses, however, is the explicit link between 'good' or 'beautiful' singing, and the affect caused by the sound, whether this manifests itself as ha?ip or the intensely emotional, physical experience of trancing-both of which are articulated as having a physical effect on the body that influences feelings of connectedness to others. This reflects Becker's argument that both religious trancers (in her case, Pentecostal), and 'deep listeners' (people who respond to music with strong emotions) may share certain strong, physiological arousal in response to music (Becker 2009). In both cases presented in this article, musical practices are deeply enmeshed in people's relationships, and the negotiation of these takes place through the emotional experiences of participating in music. Through their affective discourses, and affect-inducing practices, therefore, both groups use musical practices to deepen cooperative relationships through the emotional responses that they evoke, even though the sounds they use to do this are distinct from one another.

\section{Musical creation \& creativity}

How is 'music' conceived of as being 'created'? What are the processes by which particular combinations of sounds are organised and circulate? What significances do these sounds acquire?

During my fieldwork, Batek people regularly described songs as either being 'given' (and, conversely, sometimes 'taken away'), or as 'found' during the course of people's daily lives. They also described that one can 'look for' a song. As such, songs become kinds of 'things'. Batek people distinguish between playful singing and shamanic singing; whilst shaman songs are usually 'given' in dreams (Endicott 1979:144), more 'playful', everyday songs are 
described as being 'found' during the course of daily life. Common topics for songs may be fruits, flowers, animals, places, or experiences that are pleasurable or significant. Na?Srimjam ${ }^{\mathrm{i}}$ a Batek friend and informant in her mid twenties, sung me one example of a 'playful song' in May 2016. When pluy flowers were falling from the trees in the wind, the children at Was Yon collected the flowers to make hair decorations. Eventually, however, all the dead flowers were strewn around the lean-tos, becoming bare stalks as the petals dried and fell off. One afternoon, NaPSrimjam told me that she had 'found' (dapet) a song when she sat looking at the dead flowers while waiting for rice to boil. The song repeated the lines '?ay $t=j$ rawin de?' ('the one with a skeletal appearance') over and over. Songs such as this one are then shared around between individuals, and may change slightly from place to place as they are shared, misremembered, re-remembered or added to. Sometimes songs are remembered as 'so-and-so's' song; other times that link may eventually be forgotten. ${ }^{2}$

Like Batek shaman songs, songs containing $n \mid$ om are received by Ju|'hoansi people in dreams. Olivier describes this process below:

'In the course of his/her sleep, the healer performs the new song with the spirits of the dead people. The spirits sing in the three tessituras, whilst the healer sings a melody in the principal tessitura. The following morning, he/she sings this melody to his/her spouse without variations (repeating it identically) and the spouse follows the healer's vocal line, but tries to avoid an identical reproduction of what he/she is singing. Once the principal vocal line has been memorised, the healer then elaborates the two other melodies in the secondary tessituras. The principal vocal line is then transmitted to the other members of the village who try in turn to imitate it without exactly reproducing it. Each singer thus creates his or her own version of the melody in a tessitura which suits his or her own voice. According to the Ju|'hoansi, these versions of the melody must both flow and be different from the reference melody. Once the melodies have been memorised in the three tessituras, each singer begins to elaborate variations'

\footnotetext{
${ }^{2}$ Based on ethnographic fieldwork
} 
(Olivier 1998: 366)

Though songs will fit into pre-existing and enduring styles, new songs are created in this way all the time - in 'an incessant movement of creation, transformation, circulation, and forgetting' (Olivier 2009: 169). When songs cease to be effective for healing, as they cease to heat up $n \mid$ om, they may be changed into a new version, or replaced by new songs in a manner similar to how stories may themselves change over time as they circulate (Biesele 1993; Olivier 2009).

Healing songs might be named for the appearance that the dead person responsible for the illness has taken on. This could be a natural element (such as rain, wind, or water), or a foodstuff (such as honey), or one of many kinds of animal. It could be given the name of the illness that the person is suffering from, or for the patient him or herself, or for an animal from which Ju|'hoansi wish to protect themselves (Olivier 2001: 17). Often they are named for things that are considered 'strong', and individuals may have special allegiances with certain songs (Biesele 1993: 74). Examples from Olivier's recordings held at the British Library, made with Ju|'hoansi people in 1993 and 1995 include songs named for the following:

\section{Giraffe}

Eland

Hyena

Brown hyena

Honey

Rain

Lion

Gemsbok

Elephant 
Tsamma melon

Mongongo tree

Oryx

Kudu

Aardvark

Mamba

Snake

Rhino

Diplorrhynchus condylocarpon plant

Boscia albitrunca plant

Duiker

Wind

Child

Car

According to England (1995), among the Ju|'hoansi, instrumental music is not usually understood to contain $n \mid$ om or to be 'functional' in the same way that the medicine or initiation dances are. Like Batek instrumental music, as well as like the Ju|'hoansi's own medicine dances, these songs often (though not solely) draw on people's experiences of interaction with their environment (England 1995: 143-44). For example, on 4 November 1995 in \|Auru village, Olivier recorded the following songs with musical bow (g!omah) (British Library call number C1709/83):

Tàràkúcè

'Well-trodden path, on which you can see the traces of the tread of car tyres' 
Mòrò tzí

No meaning

Gúmí|ùi

'Cow'

!àm tzí

'When a boy plays an instrument for a girl he likes - he wants to marry the young girl, but she refuses him because she is too young'

lore

'Grewia flavescens 'rough-leafed raisin bush' which is used to make the g!omah'

|oeh!'hàn!'hàn

'Zebra'

And on the 6 November of the same year and in the same location she recorded the following 5string pluriarc songs ( $g \neq$ auka'ce) (see C1709/84).

tzí n!a'àn

Meaning unknown

!ah

'Lophotis ruficrista 'red-crested korhaan' bird'

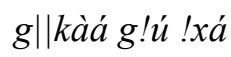

'Water in hollow of Mangetti tree' 


\section{|úín tzàmà}

'Dichrostachys cinerea, 'sickle bush', birds eat the fruits of this tree'

Batek instrumental music, like Ju|'hoansi medicine songs, also draws on people's experiences of environmental phenomena. Each of the instruments the Batek play (flute (pysol) and mouth harp (raygən or ginэy)) has a 'core repertoire' of sounds that people learn to play. These are generally recreations of sounds or experiences in the forest (Endicott (1979:152) also records the Batek's use of the log drum, but it is unclear at present if this is a recreation of any forest sound). The flute is usually used to recreate the sounds of different kinds of birds, and to play the rushing sound of rapids and the calling of gibbons. The mouth harp is used to recreate the sensation of movement, such as the flapping of birds' wings, or journeys through the forest. Though there exists this 'core repertoire' of sounds that are often played, people also play their own made-up sounds. Different people may also have idiosyncratic ways of recreating the sound of the gibbon, for example, even if that sound was always recognisable as being 'the gibbon'. 3

While both Ju|'hoansi and Batek singers and musical instrument players make use of repeating motifs, Ju|'hoan people will create melodic variations and improvise, whereas Batek people will more often than not repeat the same motif without any variation. According to England, in Ju|'hoansi !gomah (musical bow) playing 'pieces grow as they continue and the performer becomes 'more involved' in the music'. These melodic variations 'make it clear that the simple repetition of a musical pattern is not the desire of a musician - that he has, rather, musical development in mind' (England 1995: 49-50). In $\eta$ !ao (hunting bow) playing, improvisation plays an equally prominent role, 'he will return to the same pattern several times in his bow meanderings; he will wander about among the upper partials, experimenting apparently and trying to make new tunes', though 'he eventually falls back into a pattern (that is,

\footnotetext{
${ }^{3}$ Based on ethnographic fieldwork
} 
a period) to repeat it over and over any number of times with the expected variations' (England 1995: 43).

The texts of Ju|'hoansi pluriarc songs are not fixed poetic or prosodic forms that must be sung in every performance. It often happens that there are no words, even when there is a story behind the song: 'what text exists comes in the form of words or phrases, some, but not necessarily all, of which are appropriate to the theme involved' (England 1995: 144). An example of this can be found in Olivier's transcription of the first two phrases of an !ah bird pluriarc song (from British Library call number C1709/84).

[Ju|'hoansi]: !ái tzàmà $n \mid$ á mí ho

[Literal translation]: 'death - bird - that - I - see'

[Gloss]: 'When this bird emits a certain sound, the Ju|'hoansi say that someone is dead'

[Ju|'hoansi]: mí |ámá kàqá g|aí tè mí cú |'àn !ái

[Literal translation]: 'my - day - already - out of (the sun goes up) - and - I - lie - to - die'

[Gloss]: 'When someone very sick hears the sound made by this bird announcing death, they think that they will die soon'

[Olivier field notes 1995 (translated from the French by the author)]

In this example, as in others in the Olivier collection, the focus is not on an exact description, but rather on an allusive depiction of the scene through this evocative, but not descriptive, use of language. Batek songs also make more use of depictive rather than descriptive means. In the above example of the song ?ay $t=j r a w i y ~ d e ?$ ('the one with the skeletal appearance') sung by Na? Srimjam, she does not sing something along the lines of 'I found pluy flowers, but their petals had fallen off, giving them the appearance of being jrawiy ('skeletal')'. Instead, the repetition of the phrase is allusive rather than descriptive, never mentioning the name of the flower itself, but rather repeating 'the one with the skeletal appearance'. The song consisted of 
repeating that one line. This alludes to a particular experience, rather than describing the events of that moment in detail. Through playful singing, individuals therefore make references to experiences, rather than exactly describing them. Thus it is through deeply shared and cooperative lives that people bring shared meanings to these songs. However, the allusive rather than descriptive nature of songs means that the meaning of the 'creator' or singer is not imposed on the listener - rather they are invited to bring their own, individual experience to each musical moment (see also Benjamin 2013 for a discussion of this in linguistics).

The same goes for Batek musical instrument playing. While people will say 'I am playing the sound of the gibbon' or the sound of the bbaraw bird, for example, they are not attempting to exactly imitate that sound, but evoke it through extracting signifying elements of that sound. For example, when gibbon sounds are recreated on the flute, these are not exactly the same as the actual sound of the White-handed gibbon's call. Rather, a player extracts a symbolic element, in this case the characteristic ascending melisma, and creates a stylised sonic version of it. By extracting an important property of a gibbon call, the player brings into mind its actual sound (cf. Rudge in press 2019), without directly imitating it. ${ }^{4}$

While each player's rendition may be reminiscent of the swooping melismas of an actual gibbon call, there will be individual differences between flute players. Writing on Ju|'hoansi group singing, Olivier writes that "when several people sing a basic melody in the same tessitura, the result is noticeably different from one person to another... the Western ear would undoubtedly perceive these realisations as so many structurally different melodies, whilst on the contrary the Ju|'hoansi consider them as "the same whilst being a little different", (Olivier 1998:362). This is comparable to Batek storytelling practices too (Rudge 2017), and to $\mathrm{Ju}$ |'hoansi people's storytelling, according to Biesele. She points out the fact that stories are oral

\footnotetext{
${ }^{4}$ Based on ethnographic fieldwork.
} 
forms and this in itself gives them their 'constant recreative character'. Stories are never told in exactly the same way by individuals, and this is part of what makes them an 'ever-renewed source of cognitive and imaginative agreement'. Stories are never exactly the same with each retelling, and yet this does not prevent people from saying that they are 'the same story'. This kind of consensus is necessary for the intense co-operation 'made necessary by a specific form of livelihood in a given environment. The storyteller's art both 'makes sense' repeatedly and anew' (Biesele 1993: 47-48).

The ways in which songs and sounds are created and re-created in both traditions show significant differences, including idiosyncrasy within each group. At their inception, Ju|'hoansi songs are conceived of as multiple interweaving parts, and instrument playing is often accompanied by contrapuntal singing, which among the Batek is not. However, there are some commonalities in terms of people's conceptualisations of the processes of musical creation and the process of making aesthetic choices. Among both Batek and Ju|'hoansi people, songs can be found, given, or created by anyone. In Batek terminology they are, like forest foods, out there waiting to be found. In Ju|'hoan terminology they draw their 'strength' from the things in the environment for which they are named, perhaps environmental phenomena, or perhaps large game animals, or perhaps even cars. Among the Batek, often it is either songs' explicit reference to the forest, or people's personal connections of songs to the forest and their experiences in it, which cause them to evoke harip. While people explicitly describe songs as deriving from these experiences, neither group seek to exactly imitate or describe the experience that they have drawn their inspiration from. Batek people adapt sonic motifs drawn from their sonic environment, and $\mathrm{Ju}$ |'hoansi people depict experiences through allusive and depictive (rather than descriptive) speech, as do Batek people in their songs. Through the use of allusion and depiction, people use their shared experiences to evoke these experiences and associated emotion in a flexible manner. 


\section{An aesthetic of flexibility}

Having identified 'nodes' of similarity and difference in the above musical processes, and put them 'awkwardly' together, what insights can be gained? In both groups, musical practices are used as guidelines for good and beautiful ways of interacting with each other-experienced through the regulation of emotional experience, and grounded in people's bodily experiences of music. Musical practices are therefore deeply enmeshed in people's negotiation of social relationships through emotional experiences. However, each group conceptualises the specifics of how and why music acts on the body in different ways. Furthermore, both groups have separate conceptualisations of musical creation and creativity: whilst Batek people use single melodic lines, Ju|'hoansi people conceptualise music as consisting of interweaving parts, even at its very conception. Both foreground the importance of repetition, but among the Ju|'hoansi this is tied in with an aesthetic enjoyment of melodic development, whereas Batek people enjoy repetition without development. Finally, in their discourses on music and during ritual enactment of musical practices, Ju|'hoansi people foreground the dialogic and dynamic power between men and women, a practice they have in common with central and eastern African groups such as the BaYaka and Hadza (Finnegan 2013; Power 2015; Weig 2015). This is in contrast to the Batek, where such distinctions between men and women rarely come to the fore. Perhaps these distinctions in musical styles might be informative of distinctions between how egalitarianism itself is manifested in these two groups: with different focuses leaning towards a greater degree of individual autonomy among the Batek —-where music is more frequently a solo activity, than among the Ju|'hoansi, where communal medicine dances with multiple parts are more common.

There is, therefore, no single, clear, conclusion or statement to be made regarding the specifics of hunter-gatherer musical processes. However, having placed some aspects of musical process alongside one another, there are some (partial) connections that can be drawn, not 
regarding 'the nature of hunter-gatherer music' itself, but regarding how each group uses musical practices. Primarily, both groups foreground flexibility within the musical process (see also Widlok 1999: 259 on the Hai||om). This manifests itself in a depictive, allusive aesthetic (both in terms of song texts and instrument playing), that allows for multiple interpretations to coexist. This is a reflection of other practices such as storytelling (cf. Biesele 1993; Rudge 2017), and it is also a potential indicator of the balance between intense cooperation and the importance of individual autonomy so necessary for life in an egalitarian context (Endicott and Endicott 2008; Kelly 2013; Woodburn 1982, 2005), even though each group achieves this differently. Participation in musical practices can therefore be seen as fostering an orientation which, whilst highly distinct between groups, is commonly concerned with the social relationships that are flexible, dynamic, and focused on achieving the balance between cooperation and autonomy that is essential for egalitarianism, all grounded through an explicit link with emotion, the body, and the environment (so far as it is useful to separate these). While one way that Jul'hoansi people may achieve this is through learning to make interlocking parts intertwine (cf. Lewis 2012, 2013 on Mbendjele BaYaka), among both groups this aesthetic is reflected in the ways that individual interpretations and shared experiences are foregrounded simultaneously.

It would be totalising and reductive to propose that a musical aesthetic ideal of flexibility is unique to hunter-gatherers, or that there a causal link between this aesthetic, their musical practices, and their egalitarianism, especially given the diversity among these practices.

However, perhaps participating in musical processes can be seen as some of many ways in which the opportunity for an egalitarian 'social space' is created (Widlok 2016). The processes of musical interaction, and the micro-aesthetic judgements and decisions that this involves, may combine with particular other affordances in fostering particular kinds of egalitarianism, which are each unique, yet characterised by their flexibility. One could argue that music itself might be 
a 'means of managing social uncertainty', facilitated by its 'semantic indeterminacy' in comparison to language (Cross 2006: 61). The musical processes discussed above indicate an aesthetic appreciation of the kind of allusiveness that allows for the co-existence of multiple individual experiences, a kind of social skill that is also necessary in daily life. For the Batek at least, this skill may also be part of what allows people to move between hunting and gathering and participating in life outside of the forest (so long as they have the ability to access the forest). There are, therefore, aesthetic discourses, for example those surrounding $n \mid$ om, ha?ip, and musical creativity and participation, that show how hunters and gatherers may share some musical orientations, not by being the same, but rather by the ways that they themselves seek to foreground difference within inclusiveness, cooperation within autonomy, and a profound sense of flexibility amongst each other.

As Guenther has noted regarding his discussion of 'Bushman' religion, though the fluidity of religious practices are a counterpart to the fluidity of social life, anthropology's 'axiomatic assumption that religion is a culture's ultimate repository of order and meaning', make this analogy difficult to make — it is simply too fluid (1999: 5). This temptation to search for religion as a kind of order seems to parallel the pervasive view in ethnomusicology that music and social structure have an ordered or direct relationship. Attention to diversity in the musical practices of hunter-gatherers, however, demonstrates that the link between musical and social forms is not simple. What may be the case in one 'hunter-gatherer situation' (Widlok 2016) is not in another, and any connections are only 'partial' (Strathern 2004). It is important to look to the processes, aesthetic decisions, and judgements that people make more broadly. From here it is possible to begin to understand how although the musical practices of egalitarian hunting and gathering groups are vastly distinct, the aesthetic of flexibility they demonstrate may be indicative of the fluidity of egalitarianism itself. 


\section{Acknowledgements}

I wish to thank the Economic Planning Unit of the Prime Minister's Office (EPU), and the Department of Wildlife and National Parks (DWNP) for granting me permission to conduct research with Batek people in Taman Negara. For financial support, I thank the Leverhulme Trust, the Evans Fund at Cambridge, the British Library, and University College London. Universiti Sains Malaysia are also thanked for their institutional support in the course of fieldwork. I thank the British Library for awarding me the Coleridge Research Fellowship that allowed me to carry out this research, in particular Jonathan Benaim, Janet Topp Fargion, and Amelie Roper, for their help, support, and advice - alongside other members of the Unlocking Our Sound Heritage Team. Jerome Lewis is thanked for his insights on hunter-gatherer musics, as is Shzr Ee Tan for her thoughtful editing, and two anonymous reviewers for their helpful comments. Most importantly, I thank my many Batek friends for allowing me to carry out this research, and for their help, generosity, and kindness.

\section{Notes on Contributor}

Alice Rudge is a Junior Research Fellow at the Institute of Advanced Studies, University College London. She holds a PhD in Anthropology, also from University College London (2017), and was the recipient of a Coleridge Research Fellowship from the British Library (2018). Her work with the Batek focuses on the relationship between sonic practices, personhood, and the formation of ethics and aesthetics.

\section{References}

Arom, Simha. 1976. 'The Use of Play-Back Techniques in the Study of Oral Polyphonies'. Ethnomusicology 20(3): 483-519.

1984. 'The Constituting Features of Central African Rhythmic Systems: A Tentative Typology'. The World of Music 26(1): 51-67

Barnard, Alan. 2002. 'The Foraging Mode of Thought'. Senri Ecological Studies 60: 5-24.

Becker, Judith. 2009. 'Ethnomusicology and Empiricism in the Twenty-First Century'. Ethnomusicology 53(3):478-501. 
Benjamin, Geoffrey. 2013. 'Aesthetic Elements in Temiar Grammar', in The Aesthetics of Grammar, edited by Jeffrey P. Williams, 36-60. Cambridge: Cambridge University Press.

2019. 'Music and the Cline of Malayness', in Hearing Southeast Asia: Sounds of Hierarchy and Power in Context, edited by Nathan Porath, 87-116. Copenhagen: NiAS Press. Biesele, Megan. 1993. Women like Meat : The Folklore and Foraging Ideology of the Kalahari Ju/'hoan. Bloomington: Indiana University Press.

Bird-David, Nurit. 1992a. 'Beyond "The Hunting and Gathering Mode of Subsistence": CultureSensitive Observations on the Nayaka and Other Modern Hunter-Gatherers'. Man 27(1): 19.

. 1992b. 'Beyond "The Original Affluent Society": A Culturalist Reformulation [and Comments and Reply]'. Current Anthropology 33(1): 25-47.

. 1996a. 'Hunter-Gatherer Research and Cultural Diversity', in Cultural Diversity among Twentieth-Century Foragers, edited by Susan Kent, 297-304. New York: Cambridge University Press.

Bird David, Nurit. 1999. “"Animism” Revisited: Personhood, Environment, and Relational Epistemology'. Current Anthropology 40(S1): S67-91.

Bird-David, Nurit. 2005. 'The Property of Sharing: Western Analytic Notions, Nayaka and Contexts', in Property and Equality Vol. One: Ritualisation, Sharing, Egalitarianism, edited by Thomas Widlok and Wolde Gossa Tadesse, 201-216. New York: Berghan Books.

_ 2017a. 'Before Nation: Scale-Blind Anthropology and Foragers' Worlds of Relatives'. Current Anthropology 58(2): 209-226.

- 2017b. Us, Relatives : Scaling and Plural Life in a Forager World. Oakland: California : University of California Press.

Cross, Ian. 2006. 'Four Isses in the Study of Music in Evolution'. The World of Music 48(3):5563.

Dahlberg, Frances. 1981. Woman the Gatherer. New Haven: Yale University Press.

Endicott, Kirk. 1979. Batek Negrito Religion: The World-View and Rituals of a Hunting and Gathering People of Peninoular Malaysia. Oxford: Clarendon Press.

Endicott, Kirk, and Karen Lampbell Endicott. 2008. The Headman Was a Woman: The Gender Egalitarian Batek of Malaysia. Long Grove, IL: Waveland Press.

England, Nicholas M. 1967. 'Bushman Counterpoint'. Journal of the International Folk Music Council 19: 58.

1995. Music among the Z u'/'wã-Si and Related Peoples of Namibia, Botswana, and Angola. New York: Garland. 
Feld, Steven. 2012. Sound and Sentiment: Birds, Weeping, Poetics, and Song in Kaluli Expression. Durham, NC: Duke University Press.

Finnegan, Morna. 2013. 'The Politics of Eros: Ritual Dialogue and Egalitarianism in Three Central African Hunter-Gatherer Societies'. Journal of the Royal Anthropological Institute 19(4): 697-715.

- 2015. 'Dance, Play, Laugh: What Capitalism Can't Do'. Hunter Gatherer Research 1(1): 85-105.

Frisbie, Charlotte. 1971. 'Anthropological and Ethnomusicological Implications of a Comparative Analysis of Bushmen and African Pygmy Music'. Ethnology 10(3): 26590 .

Fürniss, Susanne. 2006. 'Aka Polyphony: Music, Theory, Back and Forth', in Analytical Studies in World Music, edited by Michael Tenzer, 163-204. Oxford: Oxford University Press.

Grauer, Victor. 2006. 'Echoes of Our Forgotten Ancestors'. The World of Music 48(2): 5-58. 2009. 'Concept, Style, and Structure in the Music of the African Pygmies and Bushmen: A Study in Cross-Cultural Analysis'. Ethnomusicology 53(3): 396-424.

Guenther, Mathias. 1999. Tricksters and Trancers: Bushman Religion and Society. Bloomington: Indiana University Press.

. 2007. 'Current Issues and Future Directions in Hunter-Gatherer Studies'. Anthropos 102(2): 371-88.

Howell, Signe. 1989. Society and Cosmos: Chewong of Peninsular Malaysia. Chicago: University of Chicago Press.

Ingold, Tim. 2000. The Perception of the Environment : Essays on Livelihood, Dwelling and Skill. London: Routledge.

Katz, Richard. 1982. Boiling Energy: Community Healing among the Kalahari Kung. Cambridge, MA: Harvard University Press.

Katz, Richard, Megan Biesele, and Verna Saint Denis. 1997. Healing Makes Our Hearts Happy: Spirituality \& Cultural Transformation among the Kalahari Ju/'hoansi. Rochester, VT: Inner Traditions.

Keeney, Hillary, Bradford Keeney, and Kunta Boo. 2016. 'The "Trance Dance” of the Ju/'hoan Bushmen (San) of Southern Africa: Implications for Hypnotic Means of Healing'. International Journal of Health Promotion and Education 54.3: 137-44.

Kelly, Robert L. 2013. The Lifeways of Hunter-Gatherers: The Foraging Spectrum. Cambridge: Cambridge University Press.

Kent, Susan. 1996. 'Cultural Diversity among African Foragers: Causes and Implications', in Cultural Diversity among Twentieth-Century Foragers, edited by Susan Kent, 1-18. New York: Cambridge University Press. 
Kisliuk, Michelle. 1998. Seize the Dance! : BaAka Musical Life and the Ethnography of Performance. New York: Oxford University Press.

Kricheff, Daniel Abraham, and Helmut Lukas. 2015. 'Being Maniq: Practice and Identity in the Forests of Southern Thailand'. Hunter Gatherer Research 1(2): 139-55.

Le Guin, Ursula K. 2006. 'The Carrier Bag Theory of Fiction', 165-70, in Dancing at the Edge of the World: Thoughts on Words, Women, Places. New York: Grove Press.

Lee, Richard B., and Irven DeVore (eds.). 1987. Man the Hunter: The First Intensive Survey of a Single, Crucial Stage of Human Development, Man's Once Universal Hunting Way of Life. New York: Aldine.

Lee, Richard B. 1992. 'Art, Science, or Politics? The Crisis in Hunter-Gatherer Studies', American Anthropologist 94(1): 31-54. 2003. The Dobe Ju/'hoansi. Toronto: Wadsworth.

Lewis, Jerome. 2002. 'Forest Hunter-Gatherers and Their World: A Study of the Mbendjele Yaka Pygmies and Their Secular and Religious Activities and Representations'. London: London School of Economics.

. 2008. 'Ekila: Blood, Bodies, and Egalitarian Societies'. Journal of the Royal Anthropological Institute 14(2): 297-315.

- 2009. 'As Well as Words: Congo Pygmy Hunting, Mimicry and Play', in The Cradle of Language, Volume 2: African Perspectives, edited by Rudolf Botha and Chris Knight, 232-52. Oxford: Oxford University Press.

_. 2012. 'Response to Richard Widdess: Music, Meaning and Culture', Empirical Musicology Review, 7.1: 98-101

- 2013. 'A Cross- Cultural Perspective on the Significance of Music and Dance to Culture and Society: Insight from BaYaka Pygmies', in Language, Music, and the Brain: A Mysterious Relationship, edited by Michael Arbib, 45-66. Cambridge, MA: MIT Press.

Lomax, Alan. 1971. Folk Song Style and Culture. Clinton, MA: Colonial Press Inc.

Low, Chris. 2015. 'The Role of the Body in Kalahari San Healing Dances', Hunter Gatherer Research, 1(1): 29-60.

Lye, Tuck-Po. 2005. Changing Pathways: Forest Degradation and the Batek of Pahang, Malaysia. Petaling Jaya, Malaysia: Strategic Information Research Development.

Marshall, Lorna. 1969. 'The Medicine Dance of the !Kung Bushmen'. Africa: Journal of the International African Instutite 39(4): 347-81.

Nettl, Bruno. 2001. 'An Ethnomusicologist Contemplates Universals in Musical Sound and Musical Culture', in The Origins of Music, edited by Nils Lennart Wallin, Björn Merker, and Steven Brown, 463-72. Cambridge: MIT Press. 
Olivier, Emmanuelle. 1998. 'Bushman Vocal Music: The Illusion of Polyphony', in Language, Identity, and Conceptualisation among the Khoisan, edited by Mathias Schladt, 359-70. Cologne: Rüdiger Köper Verlag.

. 2001. 'Categorizing the Jul'hoan Musical Hertiage'. African Study Monographs (Suppl. 27): 11-27.

2004. 'Performance musicale et situation sociale: Analyse de deux mises en forme d'un chant Ju|'hoan de Namibie'. Cahiers de musiques traditionnelle 17: 65.

. 2009. 'Créer, transformer, oublier'. Cahiers d'ethnomusicologie 22: 19.

Olivier, Emmanuelle, and Susanne Fürniss. 1999. 'Pygmy and Bushman Music: A New Comparative Study', in Central African Hunter Gatherers in a Multidisciplinary Perspective: Challenging Elusivenes, edited by Karen Biesbrouk, Stefan Elders, and Rossel, Gerda, 117-32. Leiden: Research School for Asian, African and Amerindian Studies.

Oloa-Biloa, Camille. 2017. 'The Egalitarian Body: A Study of Aesthetic and Emotional Processes in Massana Performances among the Mbendjele of the Likouala Region (Republic of Congo)'. Ph.D. diss., University College London, London.

Poole, Adrian. 2018. 'Comparing Timeline Rhythms in Pygmy and Bushmen Music'. Empirical Musicology Review 12(3-4): 172-93.

Power, Camilla. 2015. 'Hadza Gender Rituals - Epeme and Maitoko - Considered as Counterparts'. Hunter Gatherer Research 1(3): 333-58.

Roscoe, Paul. 2002. 'The Hunters and Gatherers of New Guinea'. Current Anthropology 43(1): 153-62.

Roseman, Marina. 1993. Healing Sounds from the Malaysian Rainforest: Temiar Music and Medicine. Berkeley: University of California Press.

Rouget, Gilbert. 2011. 'Musical Efficacy: Musicking to Survive - the Case of the Pygmies', translated by Margaret Buckner. Yearbook for Traditional Music 43: 89-121.

Rudge, Alice. In Press 2019. 'The Sounds of People and Birds: Music, Memory, and Longing among the Batek of Peninsular Malaysia'. Hunter Gatherer Research.

- 2017. 'Sound and Socio-Aesthetics among the Batek Hunter-Gatherers of Pahang State, Malaysia'. London: University College London.

Sahlins, Marshall. 1998. 'The Original Affluent Society', in Limited Wants, Unlimited Means : A Reader on Hunter-Gatherer Economics and the Environment, edited by John M. Gowdy. 5-42. Washington, D.C.: Island Press.

Seeger, Anthony. 2010. 'Oratory Is Spoken, Myth Is Told, and Song Is Sung, But They Are All Music to My Ears', in Native South American Discourse, edited by Joel Sherzer and Greg Urban, 59-82. New York: De Gruyter Mouton. 
Strathern, Marilyn. 1987. 'An Awkward Relationship: The Case of Feminism and Anthropology'. Signs 12(2): 276-92.

- 2002. 'Foreword: Not Giving the Game Away', in Anthropology, by Comparison, edited by Andre Gingrich and Richard G Fox, xiii-xvii. London: Routledge.

- 2004. Partial Connections. New York: AltaMira Press.

Testart, Alain. 1988. 'Some Major Problems in the Social Anthropology of Hunter-Gatherers [and Comments and Reply]'. Current Anthropology 29(1): 1-31.

Tsing, Anna Lowenhaupt. 2014. 'Strathern beyond the Human: Testimony of a Spore'. Theory, Culture \& Society 31(2-3): 221-41.

Weig, Doerte. 2015. 'Social Change Mirrored in Baka Dance and Movement: Observations from the River Ivindo in Gabon in 2011'. Hunter Gatherer Research 1(1): 61-83.

Widlok, Thomas. 1999. Living on Mangetti: 'Bushman' Autonomy and Namibian Independence. Oxford: Oxford University Press.

_ 2001a. 'Living on Ethnography and Comparison. What Difference Do Hai||om “Bushmen” Make to Anthropology (And Vice Versa)?'. Anthropos 96(2): 359-78.

. 2001b. 'The illusion of a future? Medicine dance rituals for the civil societyof tomorrow'. African Study Monographs Suppl.27: 165-83.

- 2016. 'Hunter-Gatherer Situations: Keynote Speech Held at the 11th Conference on Hunting and Gathering Societies (CHAGS XI) in Vienna, Austria, 7 September 2015'. Hunter Gatherer Research 2(2): 127-43.

Woodburn, James. 1982. 'Egalitarian Societies', Man, 17(3): 431-451.

- 2005. 'Egalitarian Societies Revisited', in Property and Equality Volume One: Ritualization, Sharing, Egalitarianism, edited by Thomas Widlok and Wolde Gossa Tadesse, 18-31. Oxford: Berghan Books.

\footnotetext{
${ }^{\mathrm{i}}$ Pseudonyms are used throughout the paper for Batek names
} 